\title{
The impact of tropical recirculation on polar composition
}

\author{
S. E. Strahan ${ }^{1}$, M. R. Schoeberl ${ }^{2}$, and S. D. Steenrod ${ }^{1}$ \\ ${ }^{1}$ Goddard Earth Science and Technology Center, University of Maryland, Baltimore County, Baltimore, MD, USA \\ ${ }^{2}$ NASA Goddard Space Flight Center, Greenbelt, MD, USA
}

Received: 5 November 2008 - Published in Atmos. Chem. Phys. Discuss.: 14 January 2009

Revised: 23 March 2009 - Accepted: 24 March 2009 - Published: 3 April 2009

\begin{abstract}
We derive the tropical modal age of air from an analysis of the water vapor tape recorder. We combine the observationally derived modal age with mean age of air from $\mathrm{CO}_{2}$ and $\mathrm{SF}_{6}$ to create diagnostics for the independent evaluation of the vertical transport rate and horizontal recirculation into the tropics between $16-32 \mathrm{~km}$. These diagnostics are applied to two Global Modeling Initiative (GMI) chemistry and transport model (CTM) age tracer simulations to give new insights into the tropical transport characteristics of the meteorological fields from the GEOS4-GCM and the GEOS4-DAS. Both simulations are found to have modal ages that are in reasonable agreement with the empirically derived age (i.e., transit times) over the entire altitude range. Both simulations show too little horizontal recirculation into the tropics above $22 \mathrm{~km}$, with the GEOS4-DAS fields having greater recirculation. Using $\mathrm{CH}_{4}$ as a proxy for mean age, comparisons between HALOE and model $\mathrm{CH}_{4}$ in the Antarctic demonstrate how the strength of tropical recirculation affects polar composition in both CTM experiments. Better tropical recirculation tends to improve the $\mathrm{CH}_{4}$ simulation in the Antarctic. However, mean age in the Antarctic lower stratosphere can be compromised by poor representation of tropical ascent, tropical recirculation, or vortex barrier strength. The connection between polar and tropical composition shown in this study demonstrates the importance of diagnosing each of these processes separately in order to verify the adequate representation of the processes contributing to polar composition in models.
\end{abstract}

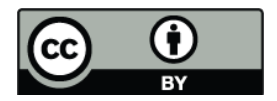

Correspondence to: S. E. Strahan (susan.e.strahan@.nasa.gov)

\section{Introduction}

An age spectrum is the distribution of transit times since a stratospheric air parcel last made contact with the troposphere. To conduct an age spectrum experiment, a pulse of inert tracer is released at a model's tropical surface or tropical tropopause, and the model is integrated with loss occurring only at the surface (Hall and Plumb, 1994). The age spectrum is then calculated by normalizing the time series of the age tracer mixing ratio at all model gridpoints. At each point in the stratosphere, a mean age of air can be calculated which can be used to qualitatively assess a model's transport circulation. Hall et al. (1999) compared mean age in more than a dozen 2-D and 3-D models and found widely different mean age distributions, suggesting a wide range of transport and mixing characteristics in the models evaluated. Mean age derived from aircraft and balloon $\mathrm{CO}_{2}$ and $\mathrm{SF}_{6}$ measurements provides the basis for evaluation of model mean age at $20 \mathrm{~km}$ (Andrews et al., 2001; Waugh and Hall, 2002). While Hall et al. (1999) found that most models did poorly in the mean age comparison at $20 \mathrm{~km}$, today many models have lower stratospheric mean age that matches observations (Eyring et al., 2006). Good mean age at $20 \mathrm{~km}$ is a necessary but not sufficient condition for a credible transport circulation because compensating transport errors can conspire to give reasonable mean age in spite of poor representation of physical processes (Schoeberl et al., 2003; Strahan and Polansky, 2006).

Complete stratospheric transport information is found in the age spectrum. The age spectrum represents the full range of transit times of the parcels arriving at a given point: a short transit time suggests that a parcel took a direct route to that point while longer times usually indicate transit through

Published by Copernicus Publications on behalf of the European Geosciences Union. 
higher levels of the stratosphere (Waugh et al., 2007). The largest peak in age spectrum, the modal age, is the most probable transit time to that point, while the average over all time elements in the age experiment, the mean age, gives information about the average transit time. Two models may have the same mean age at a particular location but comparison of their age spectra will show whether the models have the same transport pathways. Waugh et al. (2007) demonstrated the importance of transport pathways to chemical composition by comparing two models with identical mean ages in the Antarctic lower stratosphere but very different modal ages (2 years and 4 years). The model with the younger modal age had too little inorganic chlorine $\left(\mathrm{Cl}_{\mathrm{y}}\right)$ in the Antarctic vortex in spring while the model with the 4-yr modal age produced realistic $\mathrm{Cl}_{\mathrm{y}}(\sim 3 \mathrm{ppb}$ in the 1990's). Realistic transport pathways are essential for credible simulation of chemical composition.

Age spectrum experiments provide insight into model transport processes but unfortunately age spectra cannot be directly observed. Schoeberl et al. (2005) developed a technique to compute age spectra from long-lived trace gases having different lifetimes. The method requires global observations of at least 4 different species and performs a least squares fit of an assumed spectral shape using parameters that depend on each specie's loss rate. Two key pieces of information that describe the shape of an age spectrum, especially in the tropics, are the mode and the mean, and in some regions of the stratosphere they can be derived from observations. Transport in the tropical stratosphere is dominated by slow vertical advection and weak horizontal mixing (Plumb, 1996). Mote et al. (1996) found evidence for tropical isolation when they observed the upward propagation of the water vapor anomaly that results from the seasonal variation in tropical tropopause temperatures, referring to it as the water vapor tape recorder. This isolation has given rise to the label "tropical pipe" (Plumb, 1996). The upward propagation of the water vapor anomaly is a measure of the vertical transport rate, which is directly related to the modal age in the limit of low vertical mixing (Hall and Waugh, 1997; Waugh and Hall, 2002). Recently, Schoeberl et al. (2008) used 15 years of satellite measurements of tropical $\mathrm{H}_{2} \mathrm{O}$ vapor to calculate vertical velocities from $16-32 \mathrm{~km}$. Their empirically determined vertical velocities can be used to calculate transit times, providing a lower limit to tropical modal age.

Mean age can be derived from long-lived species such as $\mathrm{CO}_{2}$ and $\mathrm{SF}_{6}$ that have well-known annual growth rates in their source function. Their tropical profiles are a function of both the mean vertical ascent rate and horizontal mixing across the subtropics. Andrews et al. (2001) used aircraft measurements of $\mathrm{CO}_{2}$ to estimate mean age from $70^{\circ} \mathrm{S}-80^{\circ} \mathrm{N}$ at $20 \mathrm{~km}$, and using balloonborne measurements of $\mathrm{CO}_{2}$ and $\mathrm{SF}_{6}$ they derived mean age profiles from the tropopause to $\sim 33 \mathrm{~km}$ at $7^{\circ} \mathrm{S}, 35^{\circ} \mathrm{N}$, and $65^{\circ} \mathrm{N}$. If empirically determined tropical modal age profiles were also available, we would then have the two pieces of information needed to characterize a tropical age spectrum, that is, a spectrum consisting of a single peak with a long tail. The tropical modal age (the peak) is a diagnostic for the approximate net vertical transport rate (advection plus vertical mixing) while the mean age represents the combined effects of vertical transport and horizontal mixing with the extratropics. The separation of the mean and modal ages reflects the degree of horizontal mixing (recirculation) that occurs during ascent. When used for model evaluation, these diagnostics could show, for example, whether the cause of a model's low tropical mean age was too rapid ascent or too much tropical isolation.

In this paper we calculate modal ages in the tropical stratosphere (16-32 km) using the vertical velocities calculated from the 15-year water vapor data set in Schoeberl et al. (2008). These empirically derived modal ages are combined with tropical mean age profiles to evaluate vertical transport and tropical recirculation in Global Modeling Initiative (GMI) chemistry and transport model (CTM) simulations using meteorological fields from the Goddard Earth Observing System Version 4 (GEOS4) general circulation model (GCM) and the GEOS4 data assimilation system (DAS). We show that tropical vertical transport in the GEOS4-GCM is well simulated and that its mean age deficiency stems from too much tropical isolation. We link the behavior of age tracer and $\mathrm{CH}_{4}$ distributions to demonstrate how age in the tropical pipe affects age in the Antarctic. We compare the behavior of the GMI-GCM simulation with a GMI simulation using GEOS4-DAS meteorological fields, which have greater tropical recirculation, to see how greater recirculation affects polar composition. The importance of tropical recirculation to polar composition is demonstrated by comparisons of GMI $\mathrm{CH}_{4}$ simulations with a multi-year average of Upper Atmosphere Research Satellite (UARS) Halogen Occultation Experiment (HALOE) $\mathrm{CH}_{4}$ measurements. The results of this study stress the importance of independent diagnosis of tropical ascent, tropical recirculation, and vortex barrier strength in models so that the model processes contributing to polar composition can be individually evaluated.

\section{Observation analyses and models}

Two observational analyses are used to create diagnostics for tropical vertical transport rates (modal age) and horizontal recirculation (mean age). Tropical modal age from 16$32 \mathrm{~km}$ is approximated from the vertical velocities calculated by Schoeberl et al. (2008) from a 15-yr time series of satellite tropical water vapor measurements from the AURA Microwave Limb Sounder (MLS) (Waters et al.; 2006; Read et al., 2007) and the UARS HALOE (Russell et al., 1993). Tropical mean age profiles from 400-900 K $(\sim 18-32 \mathrm{~km})$ were derived from $\mathrm{CO}_{2}$ and $\mathrm{SF}_{6}$ balloon-borne measurements at $7^{\circ} \mathrm{S}$ by Andrews et al. (2001). To demonstrate 
the relationship between a long-lived tropospheric source gas and age tracer, we use global $\mathrm{CH}_{4}$ measurements from UARS HALOE (Russell et al., 1993) from 1993-2001. We calculate annual means and Antarctic seasonal mean profiles from the HALOE data set.

Tropical ascent and recirculation are investigated in two versions of the GMI CTM. One version used a 5-year time series of meteorological fields from the GEOS4-GCM (Bloom et al., 2005) with sea surface temperature and source gas boundary conditions for 1994-1998. The other version used a 3-year time series of 3-h time averaged meteorological fields from the GEOS4-DAS and source gas boundary conditions representing 2004-2006 (Bloom, et al., 2005). Data assimilation in GEOS4 uses a form of 3-DVar analysis, and its time-averaged meteorological fields show greatly improved stratospheric transport compared to instantaneous fields (Pawson et al., 2007). Because simulations spanning the same years of the HALOE $\mathrm{CH}_{4}$ data used here are not available, $\mathrm{CH}_{4}$ from each model has been scaled to match the global mean $\mathrm{CH}_{4}$ surface mixing ratio for the period of the HALOE observations used (19932001). This global mean was calculated from data from the NOAA Earth System Research Laboratory Global Monitoring Division (ESRL/GMD) (http://www.esrl.noaa.gov/gmd/ Photo_Gallery/GMD_Figures/ccgg_figures).

Simulations using these models are referred to as GMIGCM and GMI-DAS. Both versions have also been run with an age spectrum tracer (Hall and Plumb, 1994) and with a full troposphere-stratosphere chemical mechanism (the "Combo" model). The GMI CTM does not transport water vapor and thus a direct comparison with the observed water vapor tape recorder is not possible. In the age of air experiments, an inert tracer is released at the surface from $10^{\circ} \mathrm{S}-$ $10^{\circ} \mathrm{N}$ for 1 month; tracer loss occurs only at the surface. The GMI-DAS simulation is integrated for 20 years by recycling 1 July 2004-30 June 2005 meteorological fields; the GMIGCM recycles the 5-year sequence of wind fields four times to complete a 20-yr integration. Both versions of the CTM are integrated at $2^{\circ}$ latitude by $2.5^{\circ}$ longitude resolution with 42 vertical levels and a model lid at $0.01 \mathrm{hPa}$. Spatial resolution in the upper troposphere/lower stratosphere is $1 \mathrm{~km}$ or less. Details of the GMI Combo CTM and the credibility of its lower stratospheric transport can be found in Strahan et al. (2007) and Duncan et al. (2007).

\section{Stratospheric circulation and the tropical pipe}

\subsection{Mean and modal age in the tropics}

Figure 1 shows empirically derived tape recorder velocities and their $2 \sigma$ uncertainties from Schoeberl et al. (2008) and transit times calculated from them. The velocities, which were calculated at $2-\mathrm{km}$ intervals from $17-31 \mathrm{~km}$, are assumed to represent the mean velocity over a $2-\mathrm{km}$ range cen-
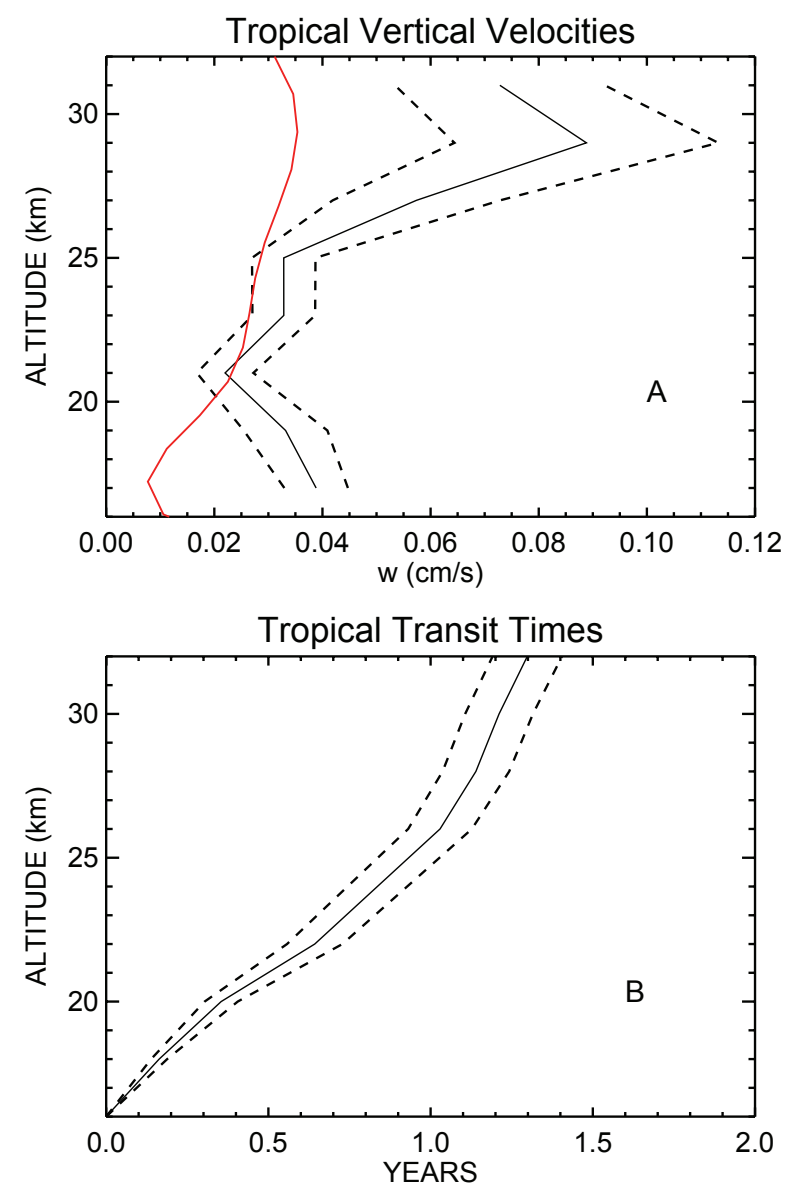

Fig. 1. (a) Tropical vertical velocities $(w)$ from the water vapor tape recorder analysis of Schoeberl et al. (2008) and the GMI-GCM annually averaged velocities calculated from vertical advection only (red), $12^{\circ} \mathrm{S}-12^{\circ} \mathrm{N}$, and (b) transit times calculated from the tape recorder vertical velocities.

tered at the level at which the velocity was derived. Uncertainty in transit time is propagated upward using the $2 \sigma$ velocity uncertainty at each level. As discussed in Schoeberl et al. (2008), their calculated velocities are in good agreement with a number of other data and model studies between $20-26 \mathrm{~km}$.

The water vapor tape recorder vertical velocity is not equivalent to the Eulerian vertical velocity nor is it exactly the residual vertical velocity (see Andrews et al., 1987, for conditions under which the residual vertical velocity is the transport velocity). Waugh and Hall (2002), however, show that for an oscillatory signal in a low diffusion environment, the bulk velocity diagnosed from the tracer oscillations approximates the modal age, although vertical mixing will cause the tape recorder to increase in tilt and thus overestimate the velocity. Thus, the velocities diagnosed from the tape recorder can be considered to be an upper limit, providing a lower limit on the transit time (modal age) due to vertical advection. 

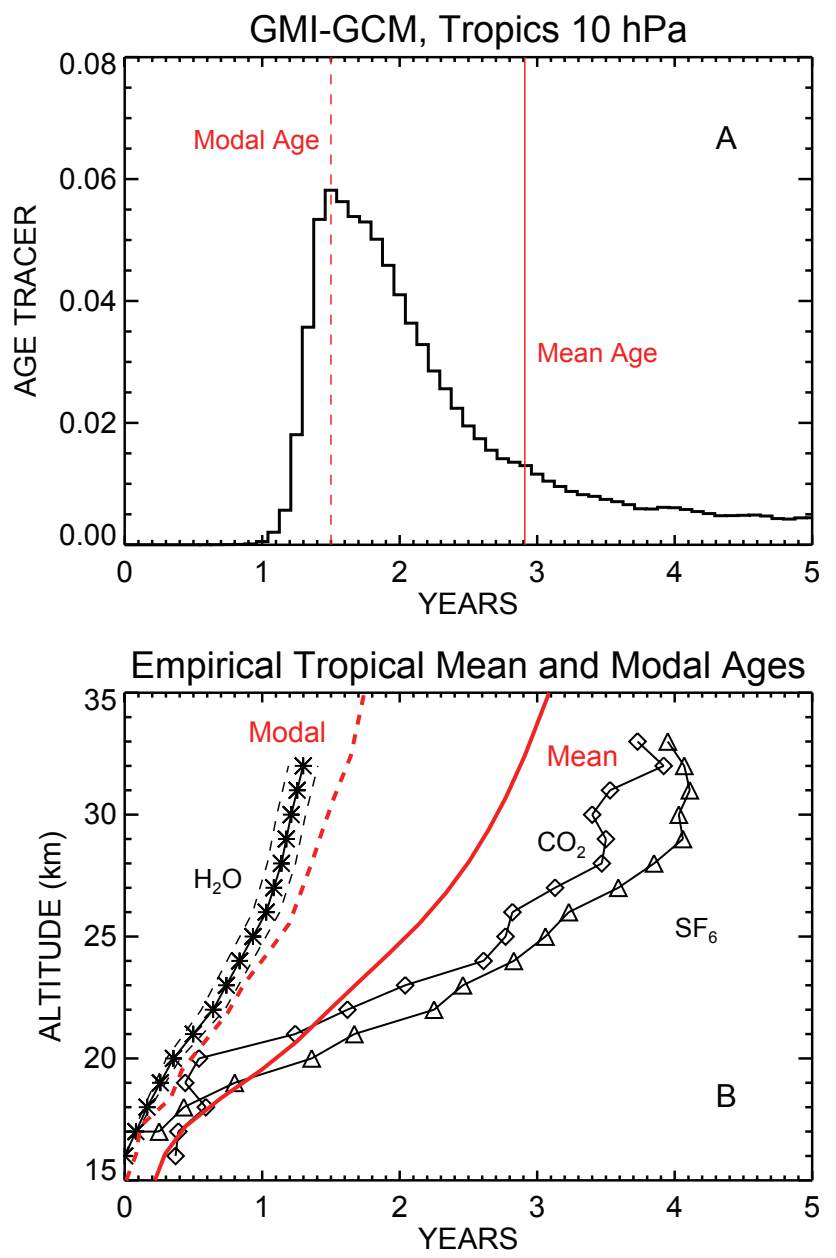

Fig. 2. (a) GMI-GCM age spectrum for $10^{\circ} \mathrm{S}-10^{\circ} \mathrm{N}, 10 \mathrm{hPa}$. Modal and mean ages are noted respectively with dotted and solid red lines; (b) Empirically derived tropical mean age from $\mathrm{CO}_{2}$ and $\mathrm{SF}_{6}$ balloon profiles (Andrews et al., 2001) and $\mathrm{H}_{2} \mathrm{O}$ tape recorder modal age with uncertainties as in Fig. 1b. GMI-GCM tropical modal age (red dashed) and mean age (red solid) age profiles are also plotted.

Figure 2 shows a tropical age spectrum from the GMIGCM middle stratosphere; this shape, a single, narrow peak followed by a long tail, is typical of both the GMI-GCM and GMI-DAS tropical age spectra. The main pulse of tracer arrives $\sim 1.5$ years after release at the surface, the result of slow ascent in the tropical pipe. The long tail of the spectrum results from the recirculation of midlatitude (older) air into the tropics. The simulation's mean age represents the integrated effects of transport by advection and mixing. We assume that mixing due to numerical diffusion and vertical diffusion are small, and thus the difference between the tropical modal and mean ages is a measure of the strength of recirculation (horizontal mixing) into the tropical pipe. If there were no tropical mixing, the mean age would equal the modal age.
Figure $2 b$ shows the modal age derived from analysis of the water vapor data in Schoeberl et al. (2008) (asterisks) and the mean age of air derived from $\mathrm{CO}_{2}$ (diamonds) and $\mathrm{SF}_{6}$ (triangles) (Andrews et al., 2001). The mean age profiles were derived from just a few balloon flights; there is no information about their seasonal or interannual variability. Above $30 \mathrm{~km}$, the $\mathrm{SF}_{6}$ age is too high because no mesospheric loss was included in the age calculation (Waugh and Hall, 2002). The mean and modal ages have significant differences by $20 \mathrm{~km}$, indicating the importance of recirculation in the lower stratosphere. The red lines in Fig. $2 \mathrm{~b}$ come from GMI-GCM tropical age spectra. The maximum of the spectrum at each level (the most probable value) is the modal age and it depends on the mean ascent rate; the modal age maxima are shown by a dashed red line. The means of the spectra, which include the effects of recirculation, are shown with the solid red line. The overlay of the empirically derived mean and modal ages shows that the GMI-GCM ascent is slightly slower than the ascent implied by the empirically derived modal age above $20 \mathrm{~km}$. This is consistent with the vertical velocity comparison shown in Fig. 1a. Between 21$27 \mathrm{~km}$, the model tropical vertical velocity is in good agreement with that derived from the tape recorder but too slow above and below this range. This results in longer transit times (higher modal ages) for the model. Because the modal ages are derived from the vertically propagating water vapor anomaly they include the effects of ascent and vertical diffusion, and therefore represent an upper limit to the vertical advective velocity. In a model age spectrum experiment, the tropical modal age is controlled primarily by the mean ascent rate; diffusion acts to broaden the width of the mode although it may also shift its altitude. The model mean age above $20 \mathrm{~km}$ is too young by up to 1.2 years, thus we conclude that the GEOS4-GCM wind fields used in the GMI-GCM create a tropical pipe that is too isolated above $20 \mathrm{~km}$. The uncertainty in the observationally derived mean age (Andrews et al., 2001) was not reported, however, the variability in the published $\mathrm{CO}_{2}$ and $\mathrm{SF}_{6}$ profiles suggests that \pm 0.5 year for mean ages above $20 \mathrm{~km}$ spans the range of observed variability.

\subsection{Methane and age}

The differences between model and observed tropical mean age are reflected in the differences between the model and HALOE $\mathrm{CH}_{4}$. Methane is long-lived in the lower and middle stratosphere but is destroyed by $\mathrm{O}^{1} \mathrm{D}, \mathrm{OH}$ and $\mathrm{Cl}$ radicals in the upper stratosphere; its annual average photochemical lifetime from $0.5-3 \mathrm{hPa}$ is $6-12$ months. Because of this, $\mathrm{CH}_{4}$ is sensitive to the amount of time spent in the upper stratosphere, which it reaches through tropical ascent, thus it is anti-correlated with age. (The correlation weakens as $\mathrm{CH}_{4}$ goes to very low values in the upper stratosphere.) Figure 3a shows the annual zonal mean $\mathrm{HALOE} \mathrm{CH}_{4}$ distribution and Fig. $3 b$ shows the annual zonal mean $\mathrm{CH}_{4}$ from the 

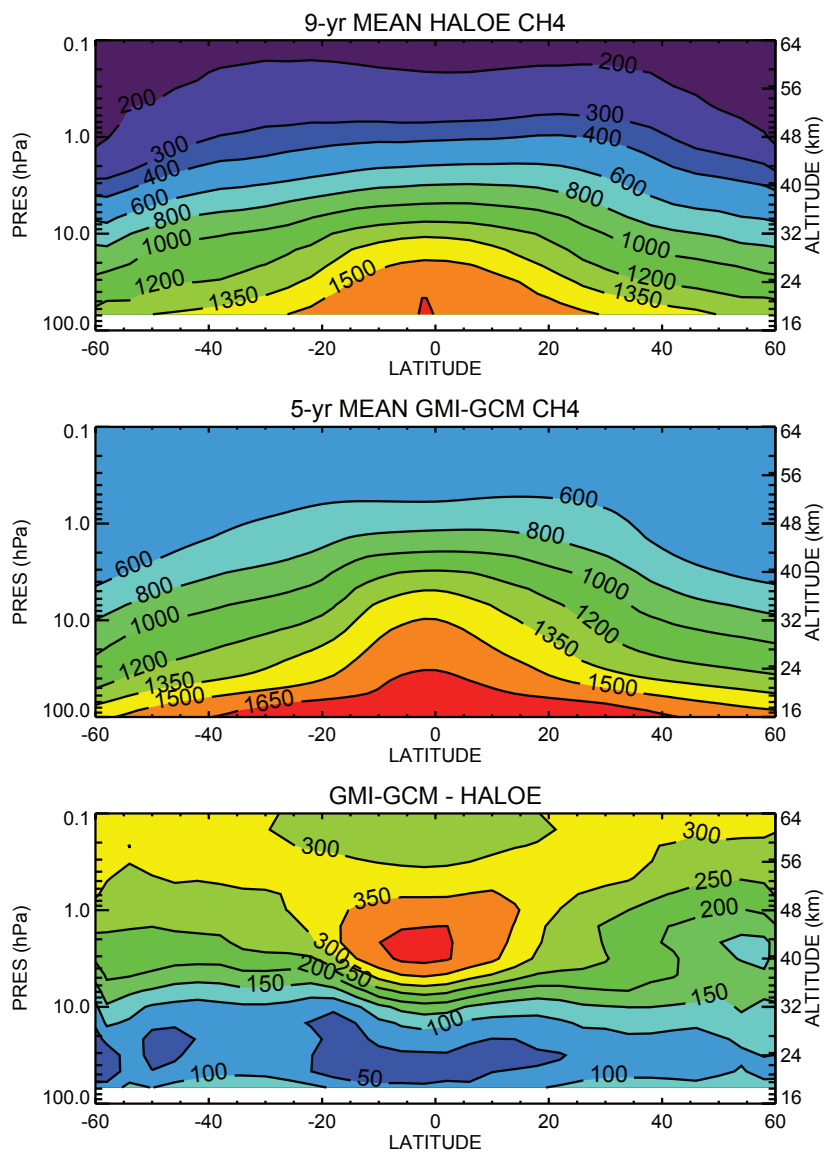

Fig. 3. (a) Zonal annual mean $\mathrm{CH}_{4}$ from 9 years of UARS HALOE observations; (b) zonal annual mean of GMI-GCM $\mathrm{CH}_{4}$ from a 5 year simulation, and (c) GMI-GCM - HALOE. Units are ppb.

GMI-GCM simulation; Figure 3c shows their differences. The model $\mathrm{CH}_{4}$ below $10 \mathrm{hPa}$ is too high by no more than $\sim 100 \mathrm{ppb}(<10 \%)$ compared to HALOE at most latitudes, but larger differences are observed above. The agreement is worst in the tropics above $4 \mathrm{hPa}$ where the model is high by more than $400 \mathrm{ppb}(\sim 100 \%)$. At $4 \mathrm{hPa}$ the lifetime is fairly long, nearly two years, suggesting that the disagreement is likely due to transport, either by too rapid upward advection in the tropics or too little recirculation through the tropical lower or middle stratosphere. The good agreement between modal ages (Fig. 2b) indicates the problem is not with the rate of vertical transport below $32 \mathrm{~km}(\sim 10 \mathrm{hPa})$. Although we cannot eliminate uncertainties in the chemical loss calculation as a contributor to the excess $\mathrm{CH}_{4}$, high $\mathrm{CH}_{4}$ caused by too little tropical recirculation is consistent with the low mean age found in the model tropical middle stratosphere.

\subsection{The effect of tropical isolation on polar composition}

Could excessive tropical pipe isolation affect the mean age elsewhere? To explore this we look at the seasonal behav-
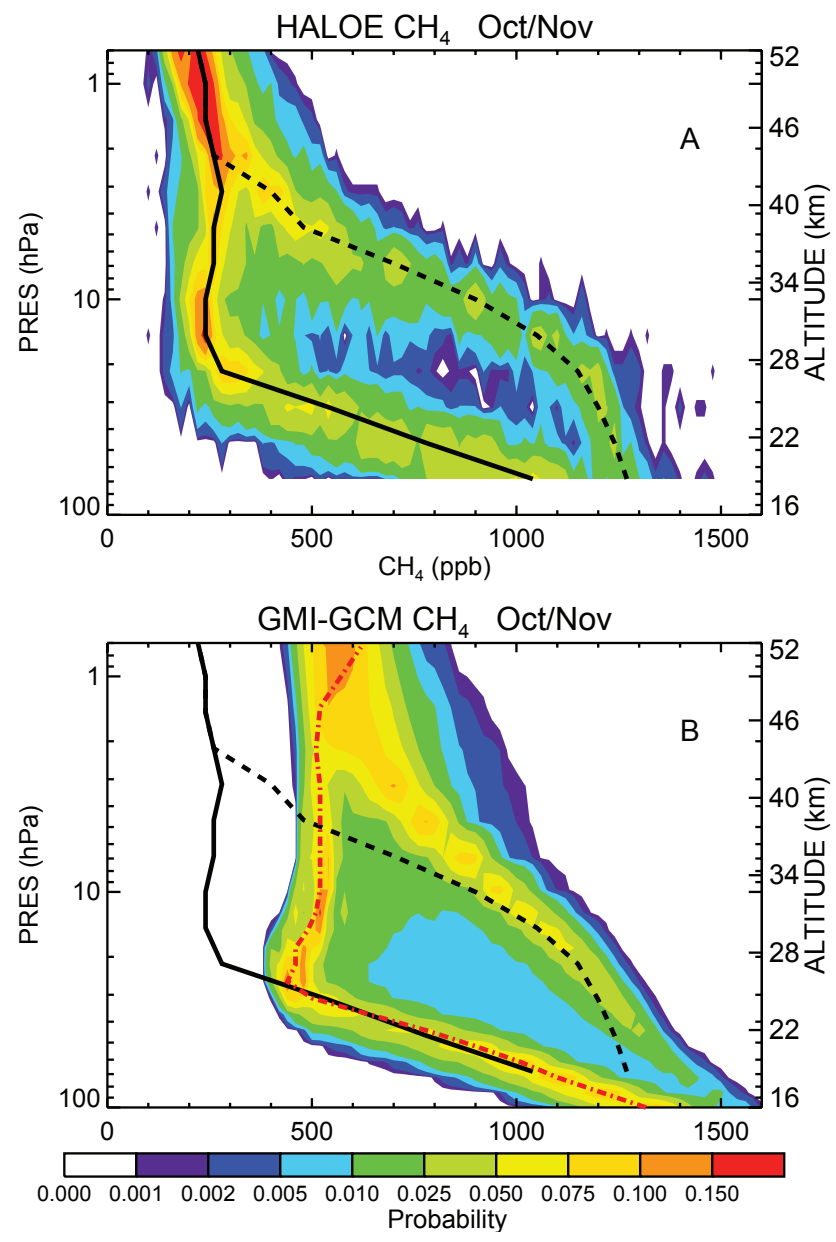

Fig. 4. (a) Contoured PDFs of 9 years of October and Novem-

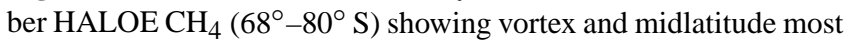
probable profiles, and (b) contoured PDFs of 5-years of October and November GMI-GCM $\mathrm{CH}_{4}\left(68^{\circ}-80^{\circ} \mathrm{S}\right)$ with overlay of HALOE most probable profiles. Red (purple) indicates highest (lowest) probability.

ior $\mathrm{HALOE} \mathrm{CH}_{4}$ in the Antarctic using $\mathrm{CH}_{4}$ as a proxy for mean age. Figure 4a shows the 9-year HALOE Antarctic vortex mean profile calculated by contouring probability distribution functions (PDFs) of observations between $80-68^{\circ} \mathrm{S}$, the highest latitudes measured by HALOE in October and November (spring). Below $3 \mathrm{hPa}$ the PDFs split into two branches, one representing deep vortex air $\left(\right.$ lower $\left.\mathrm{CH}_{4}\right)$ and the other midlatitude air (higher $\mathrm{CH}_{4}$ ). The vortex profile has low $\mathrm{CH}_{4}$, low variability and almost no vertical gradient between $0.7-20 \mathrm{hPa}$. The low $\mathrm{CH}_{4}$ values and low variability indicate high mean age in the vortex and the absence of influence by younger air. Higher $\mathrm{CH}_{4}$ in the midlatitude profile indicates the influence of younger air, and the PDF minima between the profiles demonstrate how well isolated the older vortex air is from midlatitude air. Compared with HALOE, the GMI-GCM $\mathrm{CH}_{4}$ shows many of the same 

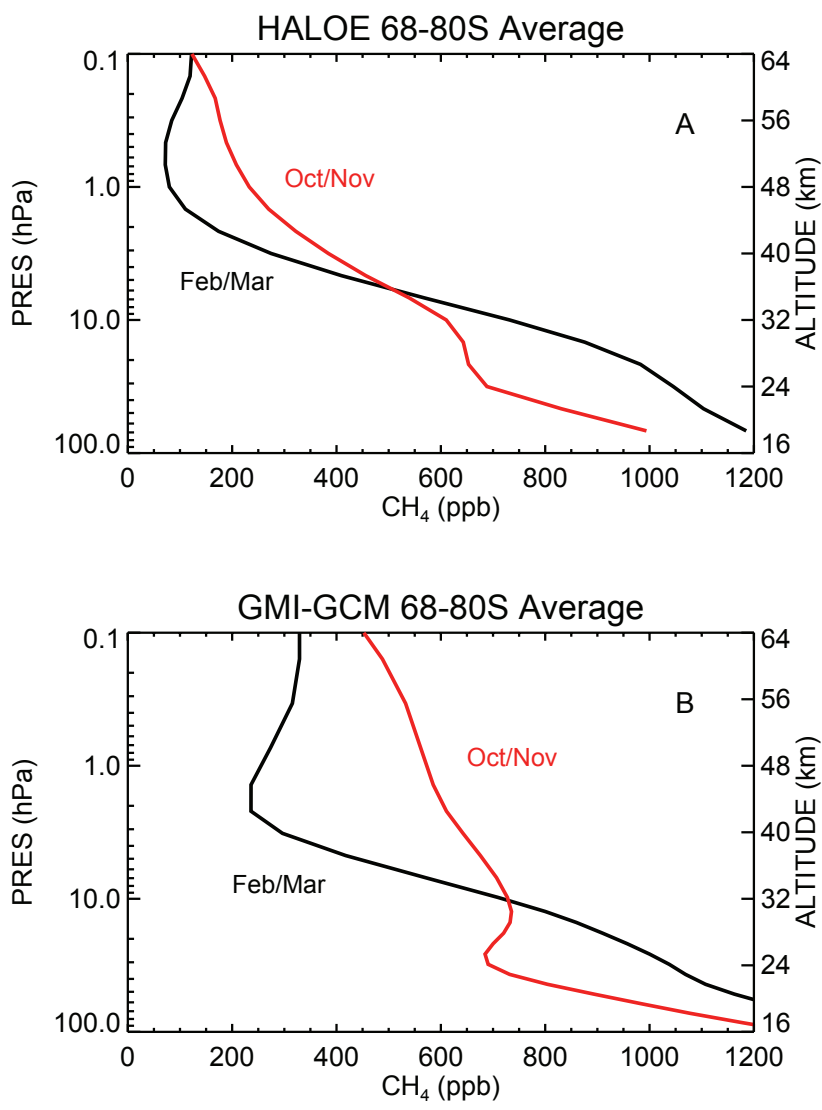

Fig. 5. (a) $\mathrm{HALOE} \mathrm{CH}_{4}$ mean profiles, $68-80^{\circ} \mathrm{S}$, for February/March and October/November; and (b) GMI-GCM CH 4 mean profiles, $68-80^{\circ} \mathrm{S}$, for the same time periods. GMI-GCM $\mathrm{CH}_{4}$ in the upper stratosphere increases by almost $400 \mathrm{ppb}$ in spring, more

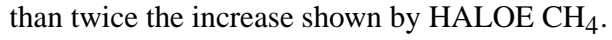

transport signatures, such as the degree of isolation indicated by the lack of vertical gradient, the bimodal PDFs, and low variability. In spite of this, model $\mathrm{CH}_{4}$ in the Antarctic upper stratosphere (Fig. 4b) is too high by $>200 \mathrm{ppb}$ and is thus too young.

The explanation may be found by considering upper stratospheric and lower mesospheric transport processes in the Antarctic fall and winter. In the austral fall, wave activity transports low latitude air to the polar region while strong cooling causes descent of mesospheric air (Rosenfield and Schoeberl, 2001; Fisher et al., 1993). Figure 5a shows the $68-80^{\circ} \mathrm{S}$ HALOE mean $\mathrm{CH}_{4}$ profiles averaged over all February and March (black) and all October and November (red) measurements. Compared to the fall profile, the HALOE spring profile (red) shows increased $\mathrm{CH}_{4}$ above $7 \mathrm{hPa}$. Descent cannot produce this increase because $\mathrm{CH}_{4}$ in the mesosphere is lower than in the upper stratosphere (Fig. 3a). The seasonal increase of more than $100 \mathrm{ppb} \mathrm{CH}_{4}$ above $7 \mathrm{hPa}$ must therefore be the result of poleward transport of high $\mathrm{CH}_{4}$ from lower latitudes in the upper strato- sphere or lower mesosphere. This increase due to poleward transport from lower latitudes in fall has also been seen in UARS CLAES $\mathrm{CH}_{4}$ data (Strahan and Douglass, 2004). The model spring profile (red), Fig. $5 \mathrm{~b}$, shows a $\mathrm{CH}_{4}$ increase of more than $300 \mathrm{ppb}$ in the upper stratosphere compared to fall, much greater than the increase observed by HALOE. As model $\mathrm{CH}_{4}$ also decreases with height in the upper atmosphere (Fig. 3b), the model's increase in spring must also be the result of horizontal transport of low latitude air in the previous seasons. Regardless of the relative contributions of descent and horizontal transport in the model, the large increase in the model Antarctic spring profile identifies the low latitude upper stratosphere as a contributor to high latitude composition. This demonstrates a pathway for tropical composition problems to be transported to Antarctic.

In contrast to the disagreement between the model and observations in the polar middle and upper stratosphere, between $30-68 \mathrm{hPa}$ the modeled and observed spring vortex profiles agree very closely (Fig. $4 b$ ). Increasing $\mathrm{CH}_{4}$ with decreasing altitude indicates the influence of younger air inside the vortex. The HALOE vortex profile increases below $20 \mathrm{hPa}$ while the model vortex increases only below $30 \mathrm{hPa}$. This difference in the height at which younger air begins to influence the model vortex is a compensating error that results in the near perfect agreement with the observations from $30-68 \mathrm{hPa}$. That is, the lack of young air influencing the model vortex from $20-30 \mathrm{hPa}$ keeps the mixing ratios constant while the observations show an increase, "catching up" with model mixing ratios at $30 \mathrm{hPa}$. This suggests that the model age spectrum in the Antarctic lower stratosphere may have too few young air elements.

\subsection{The Effect of increased tropical recirculation}

If we had a knob to turn up tropical recirculation we could test its effect on polar composition. As this is not possible, we turn instead to GMI-CTM experiments using GEOS4DAS meteorological fields which have greater tropical mean age than the GMI-GCM simulation. Figure 6a compares tropical mean and modal ages from the two CTM experiments. The GMI-DAS simulation has a lower modal age than the GMI-GCM in the tropics indicating faster vertical transport. The GMI-DAS has better agreement with the water vapor modal age, but as previously noted, the empirical modal age may contain the effects of vertical diffusion and represents an upper limit on the ascent rate. Like the GMI-GCM, the GMI-DAS mean age is too young above $22 \mathrm{~km}$ but it is consistently $\sim 0.3 \mathrm{yr}$ higher than the GMI-GCM. The difference between the mean and modal ages indicates the degree of recirculation, and this is $0.6-0.7$ years greater in the GMIDAS. Consistent with greater recirculation into the tropical pipe, the GMI-DAS tropical $\mathrm{CH}_{4}$ has a smaller disagreement with HALOE in the tropical upper stratosphere (i.e., $250 \mathrm{ppb}$ too high compared to $>400 \mathrm{ppb}$ too high in the GMI-GCM). This can be seen by comparing Fig. 6b with Fig. 3c. Lower 

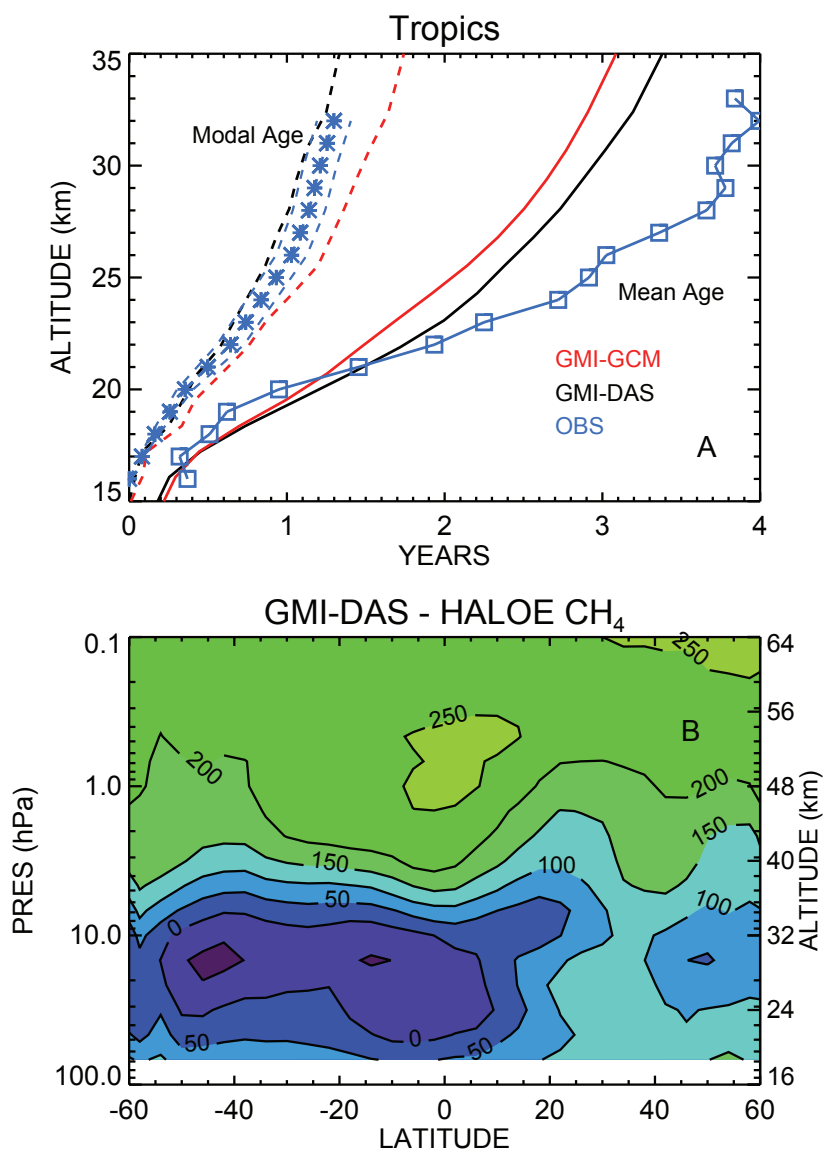

Fig. 6. (a) Tropical mean age (solid) and modal age (dashed) for GMI-GCM (red) and GMI-DAS (black), and empirical mean and modal ages (blue); (b) GMI-DAS-HALOE annual zonal mean $\mathrm{CH}_{4}$ differences. The GMI-DAS $\mathrm{CH}_{4}$ is a 3-year average.

$\mathrm{CH}_{4}$ in the GMI-DAS cannot be attributed to greater photochemical loss. GMI-DAS $\mathrm{CH}_{4}$ loss is actually $20-40 \%$ less than in the GMI-GCM in the tropical upper stratosphere because loss is controlled by $\mathrm{CH}_{4}$ abundance (temperature dependence is very weak here) and the GMI-DAS has less $\mathrm{CH}_{4}$. If photochemical losses were equal in the two simulations, tropical recirculation differences would appear even greater.

Figure 7 shows contoured PDFs of GMI-DAS $\mathrm{CH}_{4}$ from $68-80^{\circ} \mathrm{S}$ in the Antarctic spring. Similar to the GMI-GCM vortex profile (red dashed line), the GMI-DAS simulation shows vortex isolation for most of the stratosphere above $40 \mathrm{hPa}$, although the influence of younger air (higher $\left.\mathrm{CH}_{4}\right)$ in the middle stratosphere is apparent by the nonzero vertical gradient from $\sim 7-20 \mathrm{hPa}$; HALOE indicates that this influence should remain small down to $20 \mathrm{hPa}$. Above $10 \mathrm{hPa}$, the GMI-DAS vortex profile agrees better with the HALOE data (white line) than the GMI-GCM does by $\sim 100 \mathrm{ppb}$. This is similar to the differences seen in the tropics at $1 \mathrm{hPa}$ and above, where GMI-DAS $\mathrm{CH}_{4}$ is $\sim 150 \mathrm{ppb}$ higher than GMI-GCM $\mathrm{CH}_{4}$. The seasonal change in upper stratospheric

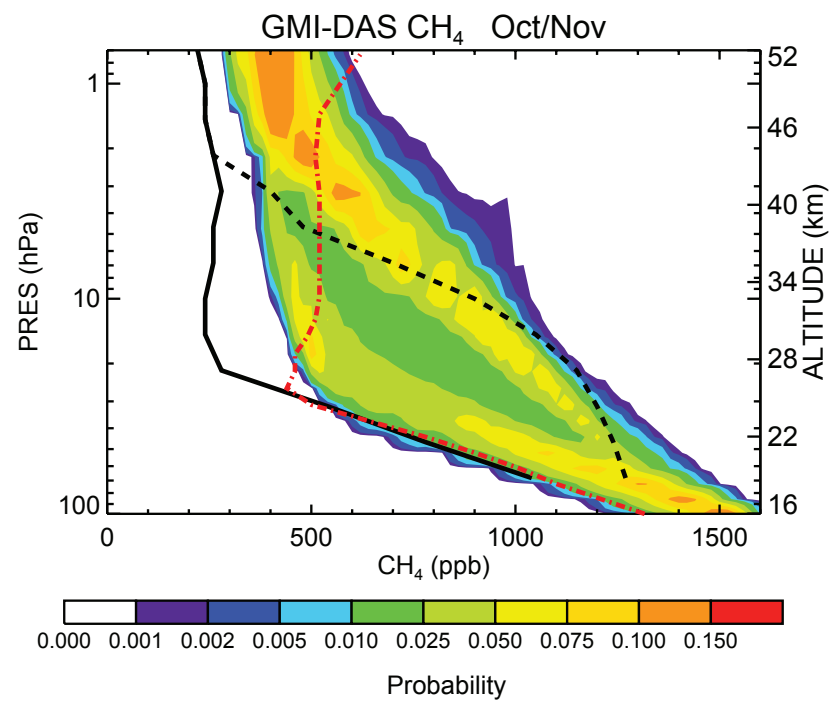

Fig. 7. Contoured PDFs of 3-years of GMI-DAS $\mathrm{CH}_{4} 68^{\circ}-80^{\circ} \mathrm{S}$ in October and November. Most probable vortex $\mathrm{CH}_{4}$ profiles for HALOE (black) and GMI-GCM (red) are overlaid. Red (purple) contours indicate highest (lowest) probability.

Antarctic profiles shown in Fig. 5 demonstrated the importance of the low latitude transport pathway to the observed spring profile. It is therefore likely that having more realistic recirculation in the tropical stratosphere leads to improved simulation of polar composition.

\subsection{Composition of the Antarctic lower stratosphere}

The composition of the Antarctic lower stratosphere is affected by the sum of the transport processes that brought air there from the middle and upper stratosphere and by the permeability of the vortex. Figure 8 illustrates the effects different processes have on age spectra. The GMI-DAS has older mean age than the GMI-GCM at $3 \mathrm{hPa}$ (Fig. 8a) because it has more age tracer in the tail of the spectrum (greater recirculation). This is consistent with October mean $\mathrm{Cl}_{\mathrm{y}}$ from these simulations, also shown in the figure, which depends strongly on mean age (Douglass et al., 2008). In the lower stratosphere, Fig. 8b, the GMI-GCM has the older mean age in spite of its younger age higher up. At $52 \mathrm{hPa}$, the GMIDAS spectra show a great deal of age tracer arriving in the first year of the simulation while the GMI-GCM has almost none. This is the signature of the leaky vortex produced by GEOS4-DAS fields which transport midlatitude (young) air directly into the vortex, resulting in a younger mean age and lower $\mathrm{Cl}_{\mathrm{y}}$ there; this was also demonstrated in Fig. 7 of Waugh et al. (2007). The lack of age tracer in the first year of the GMI-GCM Antarctic lower stratosphere is an indication of the strength of the vortex barrier; this was previously diagnosed by Strahan and Polansky (2006). While the strong vortex barrier in the GMI-GCM keeps young air out of 

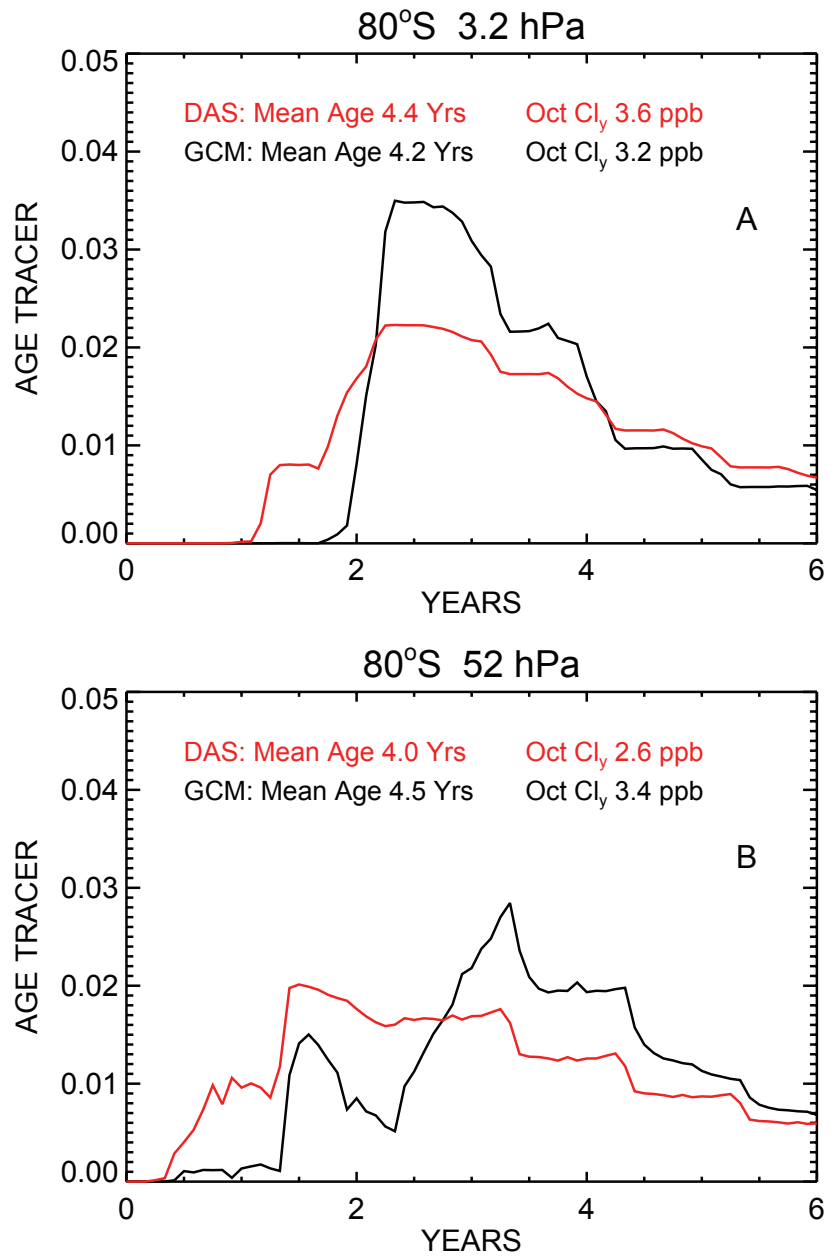

Fig. 8. Age spectra, mean age, and October mean inorganic chlorine $\left(\mathrm{Cl}_{\mathrm{y}}\right)$ at $80^{\circ} \mathrm{S}$ in the GMI-GCM (black) and the GMI-DAS (red), (a) $3.2 \mathrm{hPa}$ and (b) $52 \mathrm{hPa}$.

the vortex, because this simulation has insufficient recirculation in the tropical stratosphere, it has younger upper stratospheric air than it ought to. Thus, the early years of the GMIGCM polar lower stratospheric age spectra look better (less age tracer in the first 2 years) but the later years looks worse (shorter tail, less recirculation) - these effects are cancelled to a degree in the calculation of mean age. Two different transport deficiencies, weak tropical recirculation (i.e., the GMI-GCM) and a weak polar vortex barrier (i.e., the GMIDAS), both act to lower mean age. This is why two models having the same mean age in the polar lower stratosphere says nothing about how their transport characteristics compare. For example, the effects of an excess of (insufficient) tropical recirculation combined with a leaky (too impermeable) vortex may cancel each other out in the calculation of mean age, giving perfect agreement with the observationally derived value.

\section{Discussion and summary}

We have combined the observationally derived tropical mean age (Andrews et al., 2001) with an estimate of tropical modal age from the water vapor tape recorder to define diagnostics for the independent evaluation of vertical transport rate and horizontal recirculation into the tropics between $16-32 \mathrm{~km}$. Previous studies used a shorter time series of the $\mathrm{H}_{2} \mathrm{O}$ vapor tape recorder to determine the vertical transport rate (Mote et al., 1998), or attenuation of the $\mathrm{CO}_{2}$ seasonal cycle in the lower stratosphere to estimate horizontal mixing (Douglass et al., 1999; Waugh and Hall, 2002). This study increases the altitude range for these diagnostics to $32 \mathrm{~km}$ and uses the analysis of a much longer data record for the tropical vertical transport rate (modal age).

These diagnostics were applied to two GMI CTM experiments to give new insights into the tropical transport characteristics of two sets of meteorological fields, the GEOS4GCM and the GEOS4-DAS. Previously, the comparison of model and observed tropical profiles of $\mathrm{CH}_{4}$ suggested that the model vertical transport was too fast, or the horizontal mixing was too weak, or a combination of both. In the real atmosphere, downward control drives both the vertical transport and horizontal mixing (Haynes et al., 1991) but in a model these processes may also be affected by implementation factors such as resolution. The diagnostics presented here allow us to conclude that vertical transport rates are approximately correct in both sets of meteorological fields and that the disagreement in trace gas profiles results from insufficient recirculation of older air into the tropics. In other words, the model tropics are too isolated. Tropical isolation is greater in the GCM fields than in the DAS fields.

We have used a proxy relationship between $\mathrm{CH}_{4}$ and mean age to demonstrate how the weak recirculation into the tropics in the CTM experiments lowers mean age there and in the polar stratosphere. Examining seasonal changes in the HALOE $\mathrm{CH}_{4}$ Antarctic profiles, we identified the importance of poleward horizontal transport of low latitude, high $\mathrm{CH}_{4}$ air in austral fall to the composition of the Antarctic middle and upper stratosphere in spring. This pathway provides a means to transport mean age or composition features from the tropics to the pole. We found the same pathway to be present in the GMI-GCM simulation by comparing Antarctic summer and spring profiles; the unusually large increase in upper stratospheric $\mathrm{CH}_{4}$ came from a region where model $\mathrm{CH}_{4}$ was exceptionally high - the tropical upper stratosphere. The connection between tropical recirculation and polar composition was also demonstrated in the GMI-DAS simulation. Tropical pipe recirculation in the GMI-DAS middle stratosphere is more realistic than in the GMI-GCM, but is still weaker than observed. Greater recirculation in the GMIDAS tropical stratosphere (i.e., lower $\mathrm{CH}_{4}$ ) resulted in better agreement with HALOE $\mathrm{CH}_{4}$ in the tropics and in the Antarctic upper stratosphere in spring. 
The connection between polar and tropical composition shown in this study demonstrates the relevance of evaluating tropical transport processes in models when polar behavior is the issue of interest. Problems in tropical ascent rates or isolation have global consequences for composition. Eyring et al. (2006) showed that mean age from many of the chemistry-climate models (CCMs) participating in the WMO 2006 simulations matched the empirically derived mean age in the Antarctic lower stratosphere to within 0.5 year, but when numerous transport and dynamics diagnostics are applied to these models, significant disagreements with observations are found (Waugh and Eyring, 2008). Age spectra from these models would undoubtedly show wide variation.

Age spectra from the GMI-GCM and GMI-DAS illustrate how both tropical and polar transport processes influence mean age in the Antarctic upper and lower stratosphere. In Sect. 3.4 we showed how greater tropical recirculation in the GMI-DAS influenced the polar upper stratosphere, increasing the age tracer in the tail of the spectrum compared to the GMI-GCM. In Section 3.5, we saw how the effects of a leaky vortex decrease the GMI-DAS mean age by half a year while the strong vortex barrier of the GMI-GCM allowed mean age to increase by several months. Neither simulation shows entirely realistic transport processes, but in the case of these two models, we find that two different transport deficiencies (weak tropical recirculation in the GMI-GCM and a weak polar vortex barrier in the GMI-DAS) both lead to a lower mean age. To evaluate the credibility of CTMs and CCMs, it is essential that we separately diagnose tropical ascent rate, tropical recirculation, and vortex barrier strength in order to verify the fidelity of three important transport processes contributing to polar composition.

Acknowledgements. This work was supported by the NASA Modeling, Analysis, and Prediction Program. We thank J. Rodriguez, Project Scientist of the Global Modeling Initiative, for scientific support; E. Nielsen for producing the GEOS4-GCM fields, and S. Pawson for producing a 3-h time averaged version of the GEOS4-DAS meteorological fields. We also thank Luke Oman and Darryn Waugh for insightful comments and discussion.

Edited by: M. Dameris

\section{References}

Andrews, A. E., Boering, K. A., Daube, B. C., et al.: Mean ages of stratospheric air derived from in situ observations of $\mathrm{CO}_{2}, \mathrm{CH}_{4}$, and $\mathrm{N}_{2} \mathrm{O}$, J. Geophys. Res., 106, 32295-32314, 2001.

Andrews, D. G., Holton, J. R., and Leovy, C. B.: Middle Atmosphere Dynamics, Academic, San Diego, CA, USA, 489 pp., 1987.

Bloom, S. C., da Silva, A. M., Dee, D. P., et al.: The Goddard Earth Observation System Data Assimilation System, GEOS DAS Version 4.0.3: Documentation and Validation, NASA TM-2005104606 V26, 2005.
Douglass, A. R., Prather, M. J., Hall, T. M., Strahan, S. E., Rasch, P. J., Sparling, L. C., Coy, L., and Rodriguez, J. M.: Choosing meteorological input for the global modeling initiative assessment of high-speed aircraft, J. Geophys. Res., 104, 2754527564, 1999.

Douglass, A. R., Stolarski, R. S., Schoeberl, M. R., Jackman, C. H., Gupta, M. L., Newman, P. A., Nielsen, J. E., and Fleming, E. L.: Relationship of loss, mean age of air and the distribution of CFCs to stratospheric circulation and implications for atmospheric lifetimes, J. Geophys. Res., 113, D14309, doi:10.1029/2007JD009575, 2008.

Duncan, B. N., Strahan, S. E., Yoshida, Y., Steenrod, S. D., and Livesey, N.: Model study of cross-tropopause transport of biomass burning pollution, Atmos. Chem. Phys., 7, 3713-3736, 2007 , http://www.atmos-chem-phys.net/7/3713/2007/.

Eyring, V., Butchart, N., Waugh, D. W., et al.: Assessment of temperature, trace species, and ozone in chemistry-climate model simulations of the recent past, J. Geophys. Res., 111, D22308, doi:10.1029/2006JD007327, 2006.

Fisher, M., O’Neill, A., and Sutton, R.: Rapid descent of mesospheric air into the stratospheric polar vortex, Geophys. Res. Lett., 20, 1267-1270, 1993.

Hall, T. M. and Plumb, R. A.: Age as a diagnostic of stratospheric transport, J. Geophys. Res., 99, 1059-1070, 1994.

Hall, T. M. and Waugh, D. W.: Timescales for the stratospheric circulation derived from tracers, J. Geophys. Res., 102, 89919001, 1997.

Hall, T. M., Waugh, D. W., Boering, K. A., and Plumb, R. A.: Evaluation of transport in stratospheric models, J. Geophys. Res., 104, 18815-18839, 1999.

Haynes, P. H., Marks, C. J., McIntyre, M. E., Shepherd, T. G., and Shine, K. P.: On the "downward control" of extratropical diabatic circulations by eddy-induced mean zonal forces, J. Atmos. Sci., 48, 651-679, 1991.

Mote, P. W., Rosenlof, K. H., McIntyre, M. E., Carr, E. S., Gille, J. C., Holton, J. R., Kinnersley, J. S., Pumphrey, H. C., Russell, J. M., and Waters, J. W.: An atmospheric tape recorder: The imprint of tropical tropopause temperatures on stratospheric water vapor, J. Geophys. Res., 101, 3989-4006, 1996.

Mote, P. W., Dunkerton, T., McIntyre, M., Ray, E., Haynes, P., and Russell, J.: Vertical velocity, vertical diffusion, and dilution by midlatitude air in the tropical lower stratosphere, J. Geophys. Res., 103, 8651-8666, 1998.

Pawson, S., Stajner, I., Kawa, S. R., Hayashi, H., Tan, W.W., Nielsen, J. E., Zhu, Z., Chang, L.-P., and Livesey, N. J.: Stratospheric transport using 6-h averaged winds from a data assimilation system. J. Geophys. Res., 112, D23103, doi:10.1029/2006JD007673, 2007.

Plumb, R.: A "tropical pipe" mode of stratospheric transport, J. Geophys. Res., 101, 18569-18585, 1996.

Read, W., Lambert, A., Bacmeister, J., et al.: Aura Microwave Limb Sounder upper tropospheric and lower stratospheric $\mathrm{H}_{2} \mathrm{O}$ and relative humidity with respect to ice validation, J. Geophys. Res., 112, D24S35, doi:10.1029/2007JD008752, 2007.

Rosenfield, J. E. and Schoeberl, M. R.: On the origin of polar vortex air, J. Geophys. Res., 106, 33485-33497, 2001.

Russell, J. M., III, Tuck, A. F., Gordley, L. L., Park, J. H., Drayson, S. R., Harries, J. E., Cicerone, R. J., and Crutzen, P. J.: The 
Halogen Occultation Experiment. J. Geophys. Res., 98, 1077710797, 1993.

Schoeberl, M. R., Douglass, A. R., Zhu, Z. X., and Pawson, S.: A comparison of the lower stratospheric age spectra derived from a general circulation model and two data assimilation systems, J. Geophys. Res., 108, D4113, doi:10.1029/2002JD002652, 2003.

Schoeberl, M. R., Douglass, A. R., Polansky, B., Boone, C., Walker, K., and Bernath, P.: Estimation of stratospheric age spectrum from chemical tracers, J. Geophys. Res., 110, D21303, doi:10.1029/2005JD00125, 2005.

Schoeberl, M. R., Douglass, A. R., Stolarski, R. S., Pawson, S., Strahan, S. E., and Read, W.: Comparison of lower stratosphere tropical mean vertical velocities, J. Geophys. Res., 113, D24109, doi:10.1029/2008JD010221, 2008.

Strahan, S. E. and Douglass, A. R.: Evaluating the credibility of transport processes in simulations of ozone recovery using the Global Modeling Initiative three-dimensional model, J. Geophys. Res., D05110, doi:10.1029/2003JD004238, 2004.

Strahan, S. E. and Polansky, B. C.: Meteorological implementation issues in chemistry and transport models, Atmos. Chem. Phys., 6, 2895-2910, 2006,

http://www.atmos-chem-phys.net/6/2895/2006/.
Strahan, S. E., Duncan, B. N., and Hoor, P.: Observationally derived transport diagnostics for the lowermost stratosphere and their application to the GMI chemistry and transport model, Atmos. Chem. Phys., 7, 2435-2445, 2007, http://www.atmos-chem-phys.net/7/2435/2007/.

Waters, J. W., Froidevaux, L., Harwood, R. S., et al.: The Earth Observing System Microwave Limb Sounder (EOS MLS) on the Aura satellite, IEEE Trans. Geosci. Remote Sensing, 44, 10751092, 2006.

Waugh, D. W. and Eyring, V.: Quantitative performance metrics for stratospheric-resolving chemistry-climate models, Atmos. Chem. Phys., 8, 5699-5713, 2008, http://www.atmos-chem-phys.net/8/5699/2008/.

Waugh, D. and Hall, T.: Age of stratospheric air: Theory, Observations and Models, Rev. Geophys., 40, doi:10.1029/2000RG000101, 2002.

Waugh, D. W., Strahan, S. E., and Newman, P. A.: Sensitivity of stratospheric inorganic chlorine to differences in transport, Atmos. Chem. Phys., 7, 4935-4941, 2007. 